\title{
Quality of life in caregivers of patients with multiple myeloma
}

\section{Graça Pereira, Margarida Vilaça, Marisa Pinheiro, Gabriela Ferreira, Marta Pereira, Sara Faria, Sara Monteiro \& Rosário Bacalhau}

To cite this article: M. Graça Pereira, Margarida Vilaça, Marisa Pinheiro, Gabriela Ferreira, Marta Pereira, Sara Faria, Sara Monteiro \& Rosário Bacalhau (2020) Quality of life in caregivers of patients with multiple myeloma, Aging \& Mental Health, 24:9, 1402-1410, DOI: 10.1080/13607863.2019.1617240

To link to this article: https://doi.org/10.1080/13607863.2019.1617240

\section{Published online: 25 May 2019.}

Submit your article to this journal ๘

Џll Article views: 193

Q View related articles ¿

View Crossmark data $־$ 


\title{
Quality of life in caregivers of patients with multiple myeloma
}

\author{
M. Graça Pereira ${ }^{a, b}$ (D), Margarida Vilaça $a^{a, b}$ (D), Marisa Pinheiro ${ }^{a, b}$, Gabriela Ferreira ${ }^{a, b}$ (D), Marta Pereira ${ }^{a, b}$ (D), \\ Sara Faria ${ }^{a, b}$ (D), Sara Monteiro ${ }^{c, d}$ (ID) and Rosário Bacalhau ${ }^{a, e}$ (iD \\ ${ }^{a}$ School of Psychology, University of Minho, Braga, Portugal; ${ }^{b}$ Psychology Research Center (CIPsi), University of Minho, Braga, Portugal; \\ 'Department of Education and Psychology, University of Aveiro, Aveiro, Portugal; ${ }^{\text {d}}$ Center for Health Technologies and Services Research

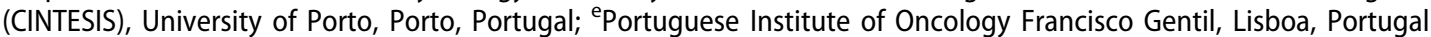

\begin{abstract}
Objectives: This study aimed to assess the relationship between sociodemographic, clinical, and psychological variables with quality of life $(\mathrm{QoL})$ and the moderating role of caregivers' age and caregiving duration in caregivers of patients with Multiple Myeloma.

Method: The sample included 118 caregivers who completed questionnaires that assessed psychological morbidity, satisfaction with social support, coping, burden, unmet needs, and QoL.

Results: High psychological morbidity, burden and information, financial and emotional unmet needs were associated with lower QoL, while higher satisfaction with social support and more effective use of coping strategies were associated with better QoL. Women caregivers reported more satisfaction with social support and those who did not choose to care reported greater financial unmet needs and more use of coping strategies. The relationship between caregivers' psychological morbidity/social support and QoL was mediated by emotional needs and double mediated by coping and burden. The caregivers' age moderated the relationship between psychological morbidity/social support and emotional needs.

Conclusion: Interventions to support the caregiver's emotional needs to promote their QoL are needed. These should be particularly tailored for older caregivers reporting greater psychological morbidity and younger caregivers less satisfied with their social support, as they have a negative indirect impact on their QoL.
\end{abstract}

\section{ARTICLE HISTORY}

Received 16 November 2018 Revised 29 April 2019 Accepted 6 May 2019

\section{KEYWORDS}

Caregivers; Multiple

Myeloma; Unmet Needs; Quality of Life

\section{Introduction}

With the advances of medicine over the years, there has been an increase in the longevity of the population and a consequent increase in chronic diseases, most of which are incapacitating and progressive, such as Multiple Myeloma (MM) (Sanchéz, Ferreira, Dupas, \& Costa, 2010). The survival rate of MM patients ranges from months to years, with an average survival of approximately 4 years, depending on early diagnosis and appropriate treatment. MM diagnosis and treatment affects not only patients but also their families (Molassiotis, Wilson, Blair, Howe, \& Cavet, 2011a), especially considering that often family members assume the caregiver role (Stenberg, Ruland, \& Miaskowski, 2009). In fact, MM patients require a full-time caregiver for at least 100 days after an allogeneic blood or marrow transplant (Simoneau et al., 2013).

Caregivers have needs, doubts, and fears, which express uncertainties about the future in terms of patients' survival and quality of life (QoL), particularly fears of death and prolonged suffering (Beattie \& Lebel, 2011; Quiñoa-Salanova, Porta-Sales, Monforte-Royo, \& Edo-Gual, 2019). On top of these uncertainties, burden negatively influences caregivers' QoL (Grant et al., 2013; La \& Yun, 2017; Lapid et al., 2016) insofar as it may affect caregivers' physical and psychological health, autonomy, and social relations (World Health Organization Quality of Life Group, 1994). Caregiving involves dedicating time to the patient, which may require caregivers to abandon their daily activities, and adjust to a new routine adapted to the demands of the patient's treatment (Grov, Dahl, Moum, \& Fossa, 2005; Stenberg et al., 2009). The burden of caregiving may restrict the number of activities the caregiver may engage in, entailing worries, insecurity and isolation, and may place the caregiver in the face of a lack of social support, thus increasing the risk of stress and fatigue (Kurtin, Lilleby, \& Spong, 2013). According to a study by Deniz and Inci (2015), caregivers of MM patients reported higher task burden and lower QoL compared to caregivers of patients with other oncology diseases. Often, due to caregiving burden, caregivers' unmet needs and ineffective coping strategies (Sequeira, 2010b) lead to psychological morbidity (Kurtin et al., 2013). In fact, several studies show that family caregivers of cancer patients in advanced stages, present higher levels of anxiety and depression (El-Jawahri et al., 2015; Simoneau et al., 2013).

According to Marques (2012), the coping strategy most used by informal caregivers is the "demand for social support". Indeed, when caregivers have social support (e.g., family, institutions, friends, or significant others) they report better QoL (Bocchi \& Angelo, 2008). Coping strategies are negatively related to caregiver burden, which may affect the perception of stress since effective coping strategies may reduce the impact of caring demands (Lazarus \& Folkman, 1984).

According to Kurtin et al. (2013), most caregivers do not have specific training to ensure the quality of care required, nor are they emotionally prepared to take on the caregiver's role, which may endanger their health and the patient's 
well-being. A study by Molassiotis et al. (2011b) with caregivers of patients with MM revealed that $34.4 \%$ felt the need to obtain more information about the disease, $27.6 \%$ reported needing to know which health care services the patient benefits from, and $26.2 \%$ reported needing help coping with changes in their lives and with appropriate emotional support. Molassiotis et al. (2011b) also concluded that a quarter of caregivers of MM patients had a chronic illness and their needs were not met, which may suggest that caregivers neglected their needs in order to meet the patient's needs. In the same study, high levels of anxiety and depression were associated with a higher level of caregivers' unmet needs that increase the burden and results in emotional distress (Girgis, Lambert, \& Lecathelinais, 2011) and a decline in QoL (Molassiotis et al., 2011b).

Overall, the literature has shown that caregivers with unmet needs showed worse psychological well-being and less social support (Chen et al., 2014); greater burden (Lambert et al., 2012) and less effective use of coping strategies (Papastavrou, Charalambous, \& Tsangari, 2012), with implications on their QoL (Molassiotis et al., 2011b). Also, as the patient's age increases, comorbidities, fragilities and syndromes associated with the aging process require a greater need for functional assistance at the beginning and during the oncological treatment (Extermann, Overcash, Lyman, Parr, \& Balducci, 1998; Mohile et al., 2011; Mohile et al., 2009), resulting in a greater perception of burden in the caregiver. Therefore, caregiver burden, unmet needs and coping may play a mediating role in the relationship between psychological morbidity, social support and QoL.

Based on the literature, this study analyses: 1) the relationship between sociodemographic/clinical/psychological variables and QoL; 2) differences on psychological variables according to caregiver's sociodemographic and clinical variables; 3 ) the mediator role of caregivers' coping, burden and unmet needs in the relationship between psychological morbidity/social support and QoL, and the moderating role of caregivers' age and caregiving duration in that relationship. We hypothesize that: 1) patients and caregiver's age, as well as caregiving duration will be negatively associated with caregivers' QoL; less burden, unmet needs, psychological morbidity, more social support and coping strategies will be positively associated with QoL; 2) caregivers who are married, employed, caregiving for the first time and not by choice, and caring for a patient in a more advanced stage of MM will manifest more burden, psychological morbidity, unmet needs, and poorer social support, coping and QoL; 3) caregivers' coping, burden and unmet needs will mediate the relationship between psychological morbidity/social support and QoL, and caregiver's age and caregiving duration will moderate that same relationship.

\section{Methods}

\section{Participants and procedure}

The sample comprised 118 caregivers of MM patients. Caregivers were recruited from four major hospitals in the North, Center and South of Portugal where patients were being followed in the medical oncology and clinical hematology's appointments. The inclusion criteria were: (a) being the caregiver of MM patients, (b) age equal to or greater than 18 years; (c) without cognitive deficit as assessed by the Mini Mental State examination (MMSE).

\section{Measures}

Hospital Anxiety and Depression Scale (HADS; Zigmond \& Snaith, 1983; Portuguese version of Pais-Ribeiro et al., 2007). This instrument has 14 items, 7 of which pertain to the Anxiety subscale and the remaining to the Depression subscale. Items are rated on a 4-point scale. A high score indicates more psychological morbidity. Cronbach's alpha in the Portuguese version was .76 for the Anxiety subscale and .82 for the Depression subscale. The global score includes the two subscales that can be used as an index of psychological morbidity or distress. In this study, the alpha for the total scale was .72 .

Social Support Satisfaction Scale (SSSS; Pais-Ribeiro, 1999). This scale evaluates satisfaction with social support, and includes 15 items distributed through four subscales: "Satisfaction with Friends", "Intimacy", "Family Satisfaction", and "Social Activities." Items are evaluated on a 5-point scale. A high score indicates a greater perception of satisfaction with social support. Cronbach's alpha of the original version for the subscale "Satisfaction with Friends" is .83, .74 for the subscales "Intimacy" and "Family Satisfaction", and .64 for subscale "Social Activities". In this study only the total scale was used. For the total scale Cronbach's alpha was .85 in the original version, and .86 in this study.

CareGiver Oncology Quality of Life Questionnaire (CarGOQoL; Minaya et al., 2012; Portuguese version of Pereira et al., in press). This instrument aims to evaluate the QoL of caregivers of cancer patients. It consists of 29 items that evaluate 10 dimensions using a 5-point scale: Psychological Well-being, Burden, Relationship with Health Care, Administration and Finances, Coping, Physical Wellbeing, Self-esteem, Leisure Time, Social Support, and Private Life. A high score indicates better QoL. Regarding the original version, Cronbach's alphas in Private Life dimension was .55 and for the remaining dimensions ranged between .72 and .89 and .90 for the total scale. In this study, only the total scale was used with a Cronbach's alpha of .82.

Carer's Assessment of Managing Index (CAMl; Nolan, Keady, \& Grant, 1995; Portuguese version of Brito, 2002). It consists of 38 items identifying coping strategies used by caregivers that yield three factors: "Dealing with Events/ Problem Solving", "Alternative Perceptions of the Situation", and "Dealing with Symptoms of Stress". Items are evaluated on 4-point scale. A high total score indicates greater use of effective coping strategies. In the Portuguese version the Cronbach alpha for the subscales ranged between .61 and .75 and was .80 . for the full scale. Only the total scale was used in the present study, with an alpha of .87 .

Burden Interview Scale (BIS; Zarit \& Zarit, 1983; Portuguese version of Sequeira, 2010a). This instrument is composed of 22 items that evaluate the objective and subjective burden of caregivers. Items are evaluated on a 5point scale and a higher score indicates a higher perception of burden. Cronbach's alpha was .84 in the original version and .93 in the Portuguese version. In this study, the Cronbach's alpha was .86 for the full scale. 
Short-Form Survivor Unmet Needs Survey (SF-SUNS; Campbell et al., 2014; Portuguese version of Pereira et al., 2019). It consists of 30 items that evaluate four domains: Information, Financial Concerns, Access and Continuity of Care, and Emotional Health. Items are evaluated on a 5point scale. For each domain a high score indicates more unsatisfied needs. The Portuguese version of the SF-SUNS presented Cronbach's alphas of $.86, .84, .76$ and .88 respectively, for the Information, Financial, Access and Emotional Health subscales. In this study, the Cronbach's alpha was .72 for the Information needs, .88 for the Financial scale, .86 for Access needs, and .93 for Emotional needs.

\section{Procedure}

This study used a cross-sectional design. The Ethical Committees of the hospitals, where data were collected, approved the study. Primary caregivers of MM patients were contacted by the patient's attending oncologist and invited to participate by the researcher, the day of the medical oncology appointment or treatment. The researcher informed the participants about the aims of the study, confidentiality of the data and voluntary participation, and they signed an informed consent for this purpose. Then, participants filled the questionnaires in the rooms available at the hospital.

\section{Data analysis}

Statistical analysis was performed using SPSS software (IBM SPSS Version 25.0). Regarding the hypotheses and which tests to be used, the normality of the distributions and the homogeneity of the variances were evaluated. The presence of multicollinearity was also tested, and the VIF value was acceptable (less than 2 ) in all variables. The Pearson correlation was used to analyse the relationship between psychological variables and caregivers' QoL. In order to assess the differences on psychological variables according to sociodemographic and clinical variables, t-tests (age, first time caregiver, caregiving by choice and marital status) and Anova (work status and caregivers disease stages) analyses were used. Unmet needs were analysed using a Manova. A hypothesized model, testing the mediator role of coping, burden and unmet needs between psychological morbidity and social support (exogenous variables) and QoL variables (endogenous variables) was evaluated using structural equation modeling (SEM) through AMOS. The chi-square statistics $\left(\chi^{2}\right)$, goodness of fit index $(\mathrm{GFI})$, comparative fit index $(\mathrm{CFI})$, standardized root mean residual (SRMR) and root mean square error of approximation (RMSEA) were used to examine the model fit. Nonsignificant $\chi^{2}$ values, CFI and GFI values equal or greater than .95 and SRMR and RMSEA values below to. 08 reflect excellent fit of a specified model to the data (Hair, Black, Babin, \& Anderson, 2010).

Finally, a multigroup analysis was employed to evaluate the role of caregivers' age and caregiving duration on the adjusted model. For that purpose and taking into consideration caregiver's age, in this sample, the latter was categorized into two groups: younger (aged 60 years or under; $N=57$ ) and older (aged between 61 and 78 years; $N=61$ ).
Table 1. Descriptive statistics for sociodemographic and clinical variables of caregivers and patients with MM $(N=118)$.

\begin{tabular}{|c|c|c|c|c|}
\hline Continuous measure & Min & Max & Mean & SD \\
\hline Age (Caregiver) & 20 & 78 & 58.67 & 13.69 \\
\hline Duration of care (months) & 2 & 240 & 42.48 & 35.55 \\
\hline Duration of daily care (hours) & 1 & 24 & 16.19 & 8.65 \\
\hline Age (Patient) & 39 & 87 & 69.65 & 9.18 \\
\hline Categorical measure & \multicolumn{2}{|c|}{$\%$ Caregivers } & \multicolumn{2}{|c|}{$\%$ Patients } \\
\hline \multicolumn{5}{|l|}{ Gender } \\
\hline Female & \multicolumn{2}{|l|}{61.9} & & \\
\hline Male & \multicolumn{2}{|l|}{38.1} & & \\
\hline \multicolumn{5}{|l|}{ Education level } \\
\hline Primary school & \multicolumn{2}{|l|}{64.4} & & \\
\hline High school & \multicolumn{2}{|l|}{20.3} & & \\
\hline College degree & \multicolumn{2}{|l|}{15.3} & & \\
\hline \multicolumn{5}{|l|}{ Employment status } \\
\hline Employed & \multicolumn{2}{|l|}{33.9} & & \\
\hline Unemployed & \multicolumn{2}{|l|}{19.5} & & \\
\hline Retired & \multicolumn{2}{|l|}{46.6} & & \\
\hline \multicolumn{5}{|l|}{ Marital Status } \\
\hline Single & \multicolumn{2}{|l|}{15.3} & & \\
\hline Married & \multicolumn{2}{|c|}{69.5} & & \\
\hline $\begin{array}{l}\text { Cohabiting with a partner } \\
\text { Divorced }\end{array}$ & \multicolumn{2}{|c|}{8.56 .8} & & \\
\hline \multicolumn{5}{|l|}{ Caregiver for the first time } \\
\hline No & \multicolumn{2}{|l|}{31.4} & & \\
\hline Yes & \multicolumn{2}{|l|}{68.6} & & \\
\hline \multicolumn{5}{|l|}{ Choose to care } \\
\hline No & \multicolumn{2}{|l|}{28.8} & & \\
\hline Yes & \multicolumn{2}{|l|}{71.2} & & \\
\hline \multicolumn{5}{|l|}{ Degree of kinship } \\
\hline Spouse & \multicolumn{2}{|l|}{55.1} & & \\
\hline Adult children & \multicolumn{2}{|l|}{33.1} & & \\
\hline Brothers & \multicolumn{2}{|l|}{5.1} & & \\
\hline $\begin{array}{l}\text { Other relatives } \\
\text { (e.g., cousin, son-in-law) }\end{array}$ & \multicolumn{2}{|c|}{6.6} & & \\
\hline \multicolumn{5}{|l|}{ Stage of MM } \\
\hline 1 & & & 37.7 & \\
\hline II & & & 30.2 & \\
\hline III & & & 32.1 & \\
\hline
\end{tabular}

Note. $\mathrm{MM}=$ Multiple Myeloma.

Likewise, caregiving duration was categorized into two groups as well: shorter (up to 24 month; $N=52$ ) and longer (more than 24 months; $N=66$ ). The chi-square value difference test $\left(\Delta \chi^{2}\right)$ and a significant level of $5 \%$ were used to compare models.

\section{Results}

\section{Sample description}

This study included $118 \mathrm{MM}$ caregivers, whose characterization is presented in Table 1.

\section{Relationship between sociodemographic, clinical, and psychological variables with QoL}

Negative associations between QoL and burden ( $r=-.741$, $p<.001)$, information needs $(r=-.277, p=.002)$, financial needs $(r=-.194, p=.035)$, emotional needs $(r=-.505, p$ $<.001)$ and psychological morbidity $(r=-.529, p<.001)$ were found. Thus, greater burden, information, financial and emotional unmet needs, and psychological morbidity were associated with lower QoL. There was a significant positive association between QoL and satisfaction with social support $(r=.443, p<.001)$ and coping $(r=.339, p$ $<.001)$. Therefore, higher satisfaction with social support and greater use of effective coping strategies were associated with better QoL. No correlations were found between QoL and access unmet needs $(r=.093, p=.316)$, caregiver's age $(r=.023, p=.809)$, patient's age $(r=.119, p=$ 
Table 2. Relationship between sociodemographic/clinical, psychological variables and QoL.

\begin{tabular}{|c|c|c|c|c|c|c|c|c|c|c|c|c|c|c|}
\hline & & 1 & 2 & 3 & 4 & 5 & 6 & 7 & 8 & 9 & 10 & 11 & 12 & 13 \\
\hline 1. & Caregiver QoL & - & & & & & & & & & & & & \\
\hline 2. & Burden & $-.741 * * *$ & - & & & & & & & & & & & \\
\hline 3. & Financial Needs & $-.194^{*}$ & .113 & - & & & & & & & & & & \\
\hline 5. & Access Needs & .093 & -.045 & $.456 * * *$ & .131 & - & & & & & & & & \\
\hline 6. & Emotional Needs & $-.505^{* * *}$ & $.406^{* * *}$ & $.353 * * *$ & $.354 * * *$ & $.332^{* * *}$ & - & & & & & & & \\
\hline 7. & Psyc. Morbidity & $-.529 * * *$ & $.629 * * *$ & .072 & $.192^{*}$ & .136 & $.503 * * *$ & - & & & & & & \\
\hline 8. & Social Support & $.443^{* * *}$ & $-.557^{* * *}$ & -.050 & $-.218^{*}$ & -.097 & $-.466 * * *$ & $.634 * * *$ & - & & & & & \\
\hline 9. & Coping & $.345^{* * *}$ & $-.458 * * *$ & $.182 *$ & -.171 & .142 & $-201^{*}$ & $-.463 * * *$ & $.532 * * *$ & - & & & & \\
\hline 10. & Caregiver's Age & .023 & .019 & $-.224 *$ & .085 & -.040 & -.021 & .047 & -.028 & -.057 & - & & & \\
\hline 11. & Patient's Age & .119 & -.182 & .165 & -.045 & -.023 & -.151 & $-.273^{* *}$ & $.262 * *$ & .157 & -.125 & - & & \\
\hline 12. & Caregiving Daily Care & -.145 & .083 & -.110 & .122 & -.058 & -.007 & .079 & .032 & .013 & $.492 * * *$ & -.123 & - & \\
\hline 13. & Caregiving Duration & -.167 & .177 & .102 & $.196^{*}$ & .098 & .171 & .122 & $-.188^{*}$ & -.178 & $.281^{* *}$ & .035 & .162 & - \\
\hline
\end{tabular}

Note. $* p<.05 ; * * p<.01 ; * * * p<.001$.

$.224)$, caregiving daily care $(r=-.145, p=.118)$, and caregiving duration $(r=-.167, p=.071)$ (Table 2).

\section{Differences in psychological variables according to caregivers' sex, first time caregiving, choice to be a caregiver, marital status, work status and patient's disease stage}

According to caregivers' sex, no significant differences were found regarding unmet needs $[F(4,113)=.599, p=.664$ $\left.\eta^{2}=.021\right]$. In the same sense, no significant differences were found regarding psychological morbidity $(t=.749, p$ $=.455)$, coping strategies ( $t=-1.397, p=.165)$, burden $(t$ $=.343, p=.732)$, and QoL ( $t=-.151, p=.880)$. Satisfaction with social support $(t=-2.162, p=.033)$ presented significant differences in scores for males $(M=56.02, S D=10.01)$ and females $(M=60.32, S D=10.76)$.

In terms of being/not being a first time caregiver, no significant differences were found regarding unmet needs $\left[F(4,113)=.555, p=.696, \eta^{2}=.019\right]$, psychological morbidity $(t=.494, p=.623)$, satisfaction with social support $(t=$ $.500, p=.618)$, coping strategies $(t=1.156, p=.250)$, burden $(t=-1.151, p=.252)$, and QoL $(t=.500, p=.618)$.

Differences were only found in financial unmet needs $(t=2.623, p=.012)$ and coping strategies $(t=2.996, p=$ $.003)$, according to intentional versus non-intentional choice as a caregiver. Caregivers who did not choose the caregiver role reported greater financial unmet needs $(M=8.09$, $S D=7.75)$ and more use of coping strategies $(M=107.88$, $S D=18.23)$ compared with caregivers who deliberately chose to care for the patient (financial needs: $M=4.42$, $S D=4.03$; coping: $M=96.61, S D=18.63$ ).

In terms of the caregivers' marital status (being married/ common law union versus being single/divorced), there were no differences on unmet needs $[F(4,113)=1.113, p=$ $\left..354, \eta^{2}=.038\right]$, psychological morbidity $(t=1.236, p=$ $.219)$, satisfaction with social support $(t=-.716, p=.475)$, coping strategies $(t=-.773, p=.441)$, burden $(t=.978, p$ $=.330)$, and QoL $(t=-1.571, p=.119)$.

Regarding MM stage (I, II and III), there were no significant differences on unmet needs $[F(4,88)=.875, p=539$, $\left.\eta^{2}=.038\right]$, psychological morbidity $[F(2,91)=.146, p=.864]$, satisfaction with social support $[F(2,91)=.245, p=.783]$, coping strategies $[F(2,91)=.507, p=.604]$, burden $[F(2,91)$ $=1.329, p=.270]$, and QoL $[F(2,91)=.587, p=.558]$.

Finally, analyses regarding work status (employed, unemployed and retired), did not reveal significant differences on unmet needs $\left[F(4,112)=1.951, p=.054, \eta^{2}=.065\right]$, psychological morbidity $[F(2,115)=.445, p=.642]$, satisfaction with social support $[F(2,115)=2.953, p=.056]$, coping strategies $[F(2,115)=.601, p=.550]$, burden $[F(2,115)=$ $1.062, p=.349]$, and QoL $[F(2,115)=.067, p=.935]$.

\section{Path analysis model}

The impact of the caregivers' psychological morbidity and social support on QoL, mediated by coping strategies, burden and unmet needs, as hypothesized, was analysed through a path analysis. The estimated values of the fit indices indicated that the global fit of the model was not adequate (Figure 1): $\left(\chi_{(12)}^{2}=46.69, p=.000\right), \mathrm{GFI}(.907)$, CFI (.900), SRMR (.092) and the RMSEA (.157).

The final adjusted model according to the modification indices showed a good fit $\left(\chi_{(17)}^{2}=8.39, p=.211, \mathrm{GFI}=\right.$ $.977, \mathrm{CFI}=.992$, SRMR $=.038$, RMSEA $=.058$ ). As presented in Figure 2, the indirect effect of psychological morbidity on QoL was fully mediated by burden $(\beta=-.466, p$ $<.001)$, and double mediated by coping strategies and burden ( $\beta=-.157, p=.004$ ). The effect of social support on QoL was also fully mediated by coping strategies and burden $(\beta=.181, p=.001)$. Finally, emotional unmet needs fully mediated the effect of psychological morbidity $(\beta=-.254, p<.001)$ and social support $(\beta=.235, p=$ .001) on QoL. As predicted, psychological morbidity showed a negative association with social support $(\beta=$ -37.96, $p<.001)$.

\section{The moderator role of age}

A multigroup analysis using younger versus older caregivers indicated that the adjusted model without any constrain (free effects for the two groups) and the fully constrained model (same effects for the two groups) were significantly different $\left(\Delta \chi^{2}{ }_{(8)}=19.11 ; p=.014\right)$ (Table 3). Thus, the caregivers' age had a significant effect on the adjusted hypothesized model. Specifically, the relationship between psychological morbidity and emotional unmet needs was positive and significant in the older caregivers group ( $\beta=$ $.985, p<.001)$, but not in the younger group $(\beta=-.014, p$ $=.948$ ), revealing a stronger relationship between those variables, in older caregivers. Also, the relationship between satisfaction with social support and emotional unmet needs was negative and significant in the younger caregivers $(\beta=$ $-.447, p<.001)$, contrary to the older caregivers $(\beta=.048, p$ $=.632$ ), indicating that the relationship was stronger when caregivers were younger. 


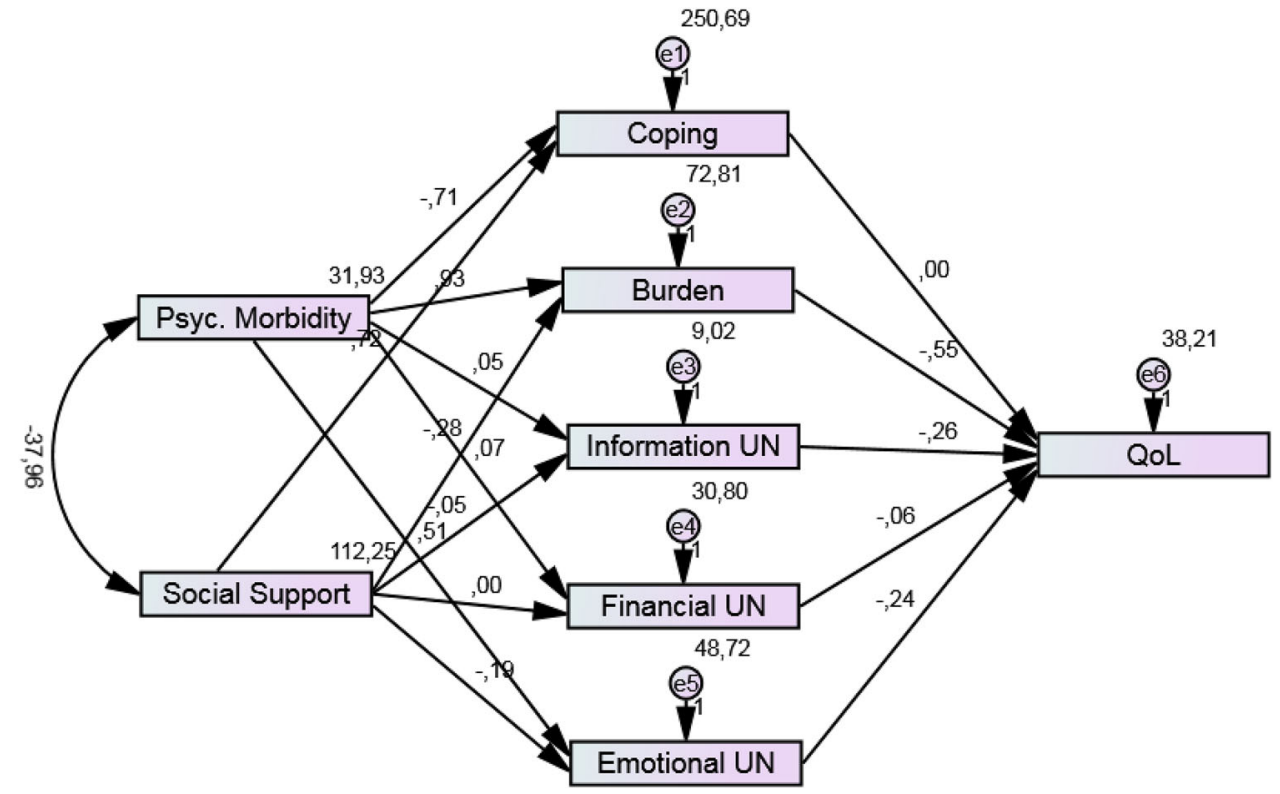

Figure 1. Results of the caregivers' hypothesized model.

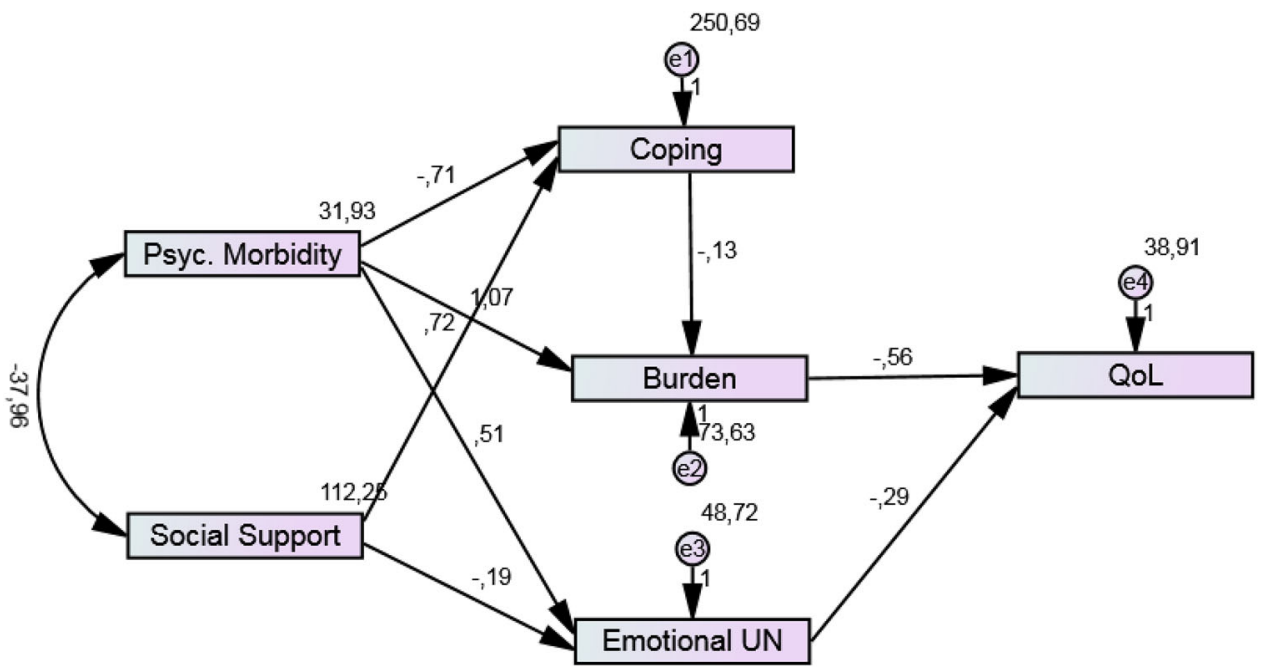

Figure 2. Results of the caregivers' adjusted model.

Table 3. Multigroup analysis in groups of younger $(\leq 60$ years; $n=57)$ versus older $(61-78$ years; $n=61)$ caregivers and shorter ( $\leq 24$ months; $n=52$ ) versus longer ( $>24$ months; $n=66)$ caregiving duration.

\begin{tabular}{lcrrrrrr}
\hline & $\chi^{2}$ & $d f$ & $p$ & RMSEA & RMSEA Cl $l_{90 \%}$ & SRMR & GFI \\
\hline Younger vs. Older & & & & & & & \\
(M1) Unconstrained & 12.77 & 12 & .386 & .023 & $.000-.099$ & .0487 & .965 \\
(M2) Full constrained & 31.88 & 20 & .045 & .072 & $.011-.116$ & .0708 & .920 \\
M2 vs. M1 & 19.11 & 8 & .014 & & & & \\
Partial constrained & & & & & & & \\
(M3) Morbidity to Relationship & 24.74 & 13 & .025 & .088 & $.031-.141$ & .0621 & .937 \\
M3 vs. M1 & 11.97 & 1 & .001 & & & & \\
(M4) Social support to Relationship & 23.21 & 13 & .039 & .082 & $.018-.136$ & .0660 & .940 \\
M4 vs. M1 & 10.44 & 1 & .001 & & & & \\
Shorter vs. Longer & 14.29 & 12 & .283 & .041 & $.000-.107$ & .0471 & .962 \\
(M1) Unconstrained & 20.47 & 20 & .429 & .014 & $.000-.082$ & .0589 & .948 \\
(M2) Full constrained & 6.175 & 8 & .628 & & & & \\
M2 vs. M1 & & & & & &
\end{tabular}

\section{The moderator role of caregiving duration}

The results of the multigroup analysis using caregivers who cared up to 24 months versus more than 24 months showed that the caregiving duration was not a moderator in the adjusted hypothesized model's results $\left(\Delta \chi^{2}{ }_{(8)}=6.175 ; p\right.$ $=.628)$ (Table 3).

\section{Discussion}

In this study, caregivers were mostly female and patients' spouses or adult children, which is in accordance with the studies by Molassiotis et al. (2011b) and Rha et al. (2015). Higher information, financial and emotional unmet needs 
were associated with poorer QoL, as predicted. In fact, caregivers who are emotionally and financially in need and report more information needs are more vulnerable to the impact of caring (Grimm, Zawacki, Mock, Krumm, \& Frink, 2000), as they may not have the necessary skills to care for a patient with MM (Chen et al., 2014). Psychological morbidity was also associated with a decrease in QoL (Madore, 2015) in caregivers, since the uncertainties, fears, and concerns about the future of the patient negatively impact their QoL. Not surprisingly, burden was also associated with psychological morbidity and a decrease in caregivers' QoL (Sequeira, 2010b).

Higher satisfaction with social support and the use of coping strategies were associated with better caregiver's QoL, suggesting they may act as protective factors, i.e. buffer against the impact of psychological morbidity on QoL. Overall, hypothesis 1 was confirmed.

Female caregivers reported more satisfaction with social support, compared to male caregivers. In fact, considering that women are often the predominant provider of informal care, as socially and culturally expected, and therefore more permeable to caregiving adverse effects (Schrank et al., 2016), it makes sense that they report more availability to resort to their social support network. However, evidence from gender differences' studies in caregiving is not consensual and further research on this area is required. Caregivers who did not intentionally choose to care for the patient reported greater financial unmet needs and more use of coping strategies. This result is in agreement with the literature, since caregivers that did not choose the caregiver role had less opportunity to prepare for patient's needs regarding the illness and treatment (Kristjanson \& White, 2002). Also, the possible unprepared transition to the caregiver role may require a greater use of coping strategies to successfully respond to the caring demands. Thus, hypothesis 2 was also partially confirmed, since no differences on psychological variables were found, according to caregivers' marital status, being a first time caregiver, work status and MM stage. In fact, although the literature suggests that female caregivers report more unmet needs (Friðriksdóttir et al., 2011; Kim, Han, Shaw, McTavish, \& Gustafson, 2010; Lambert et al., 2012), distress (Northouse, Katapodi, Schafenacker, \& Weiss, 2012), burden (Teixeira \& Pereira, 2013), and worse QoL (Lambert et al., 2012), other studies have found no differences according to the sociodemographic (Kim, Kashy, Spillers, \& Evans, 2009; Lambert et al., 2012; Simoneau et al., 2013; Sklenarova et al., 2015) and clinical variables (Lambert et al., 2012; Sklenarova et al., 2015).

In relation to the hypothesized model regarding the caregivers' psychological variables, emotional unmet needs were the only unmet need playing a significant mediator role. In fact, a study developed with family caregivers of cancer patients indicated that caregivers often turned to coping strategies focused on emotion to deal with the burden of caregiving (Papastavrou et al., 2012). Psychological morbidity had a negative direct effect on coping, which is consistent with previous findings that suggest that emotional distress escalates when a person concludes that there is little they can do to manage events or threats faced as a result of cancer (Fitch \& Maamoun, 2016). The direct positive effect of psychological morbidity on emotional needs was also not surprising, since distress significantly interferes with the ability to take care of the patient and to provide emotional and instrumental support. The mediator role of coping between psychological morbidity and burden was also predicted, considering that the caregiver often takes great responsibility for daily caregiving, probably representing the most important source of patient' support, and taking into consideration that psychological morbidity may interferes with burden, through the perception of fewer available coping resources to deal with the demands of caregiving, making these demands even more challenging, increasing the perception of burden.

The direct effect of social support on coping is also in accordance with the literature, as previous studies demonstrated that social support can function as coping assistance strategy (Kim, Han, et al., 2010; O'Brien \& DeLongis, 1997). The indirect effect of social support on QoL was also fully mediated by emotional needs. Particularly, higher satisfaction with social support was associated with lower emotional unmet needs. Indeed, this negative relationship has also been reported in other studies (Friðriksdóttir et al., 2011; Lambert et al., 2012). However, in spite of several studies that have suggested that more emotional unmet needs were associated with worse QoL (Friðriksdóttir et al., 2011; Kim, Kashy, et al., 2009; Park et al., 2010), in the present study, satisfaction with social support only contributed to the caregivers' QoL, when emotional needs were met. Considering that a significant percentage of our sample is professionally active, caregivers may neglect their own support needs, worsening their QoL and increasing their levels of emotional distress (Printz, 2011). Social support, as previously noted, has been suggested as a valuable resource to cope with the disease. One may hypothesize that these caregivers adopt coping skills, such as social support, to manage their own distress and, probably, also patients' distress (Lambert et al., 2012); and when their emotional needs are met, their QoL may also improve.

The indirect effects of caregivers' psychological morbidity on QoL were also fully mediated by emotional needs. Actually, it makes intuitive-sense that, if caregivers had more emotional needs, i.e., difficulty on talking about their emotions and cope with negative feelings, they are more likely to experience symptoms of anxiety and depression. Although several studies have shown that caregivers with higher levels of distress report poorer mental health and worse QoL at several levels (Friðriksdóttir et al., 2011; Fujinami et al., 2015), in this sample of MM caregivers, distress only contributed to caregivers' QoL, when they reported more emotional needs.

Finally, the indirect effects of caregivers' psychological morbidity on QoL were fully mediated by burden. Previous literature has suggested that caregivers who show distress, anxiety or depression are more likely to report burden (Applebaum et al., 2016; Cooke, Grant, Eldredge, Maziarz, \& Nail, 2011). On the other hand, the burden that is related to direct, indirect care and other responsibilities, which imply constant changes in the daily routine (Stenberg et al., 2009), are related to caregivers' poor QoL (La \& Yun, 2017). So, hypothesis 3 was also partially confirmed.

Considering, the moderating role of the caregivers' age in the hypothesized model, results indicated that the effect of psychological morbidity on emotional needs was 
significantly stronger in older caregivers. Although several studies have pointed out that younger caregivers are more likely to report more psychological distress, due to demands of informal cancer care together with other life course roles (e.g., childrearing, employment) (Gaugler et al., 2005; Kim, Baker, Spillers, \& Wellisch, 2006), it is possible that employment outside the home can play a buffering effect on psychological morbidity and represent some respite from the cancer experience (Swanberg, 2006). Also, the stronger effect of social support on emotional needs in younger caregivers makes sense since those caregivers seem to place greater value on their social relations, reporting more frequent contact with their social support network. Also, younger caregivers experience more social stress as a result of their multiple social, professional, and domestic responsibilities (Kim et al., 2006) and the effect of social support can be understood as stronger particularly for burdened caregivers (Teixeira \& Pereira, 2013).

Contrary to what was hypothesized, the caregiving duration did not moderate the relationship between the adjusted model variables, in contrast to prior research (Gaugler et al. 2005; Stenberg et al., 2014), suggesting that when time since diagnosis or the onset of cancer treatment increases, caregivers tend to report less emotional and psychological distress. However, considering that MM disease has been presenting an increasing survivorship due to improved diagnosis and treatment, which enhances the complexity and caregiving duration, further research is needed regarding MM caregivers' long-term care.

\section{Limitations}

This study has some limitations that should be addressed, such as the cross-sectional design that does not allow to establish causal relationships and the exclusive use of selfreport measures. Future studies should include larger samples and longitudinal designs to assess the changes over time in caregivers taking into consideration coping, burden and unmet needs and their impact on caregivers' QoL. It is also important to assess, in future studies, the mediator role of positive variables such as benefit finding and purpose in life to name a few.

\section{Conclusion}

This study showed that informal caregivers with greater psychological morbidity, burden and higher information, financial and emotional unmet needs reported poorer QoL. Higher satisfaction with social support and the use of coping strategies were associated with better QoL. These results are important for psychological intervention programs in order to design and provide the support to the caregiver's psychological needs promoting their QoL. Furthermore, since emotional needs had a preeminent mediator role, psychological intervention programs should particularly target these needs. Finally, interventions should be tailored particularly for older caregiver who experience greater psychological morbidity and younger caregivers that report less satisfaction with social support, as those have a negative indirect impact on their QoL.

The results of this study may also contribute to reinforce the importance of government policies, in providing appropriate strategies to help the caregiver' tasks in caring for oncological patients.

\section{Disclosure statement}

The authors report no conflict of interest.

\section{Funding}

This study was supported by a grant from the Portuguese Associations of Portuguese Association against Leukemia and the Portuguese Association of Leukemias and Lymphomas.

\section{ORCID}

M. Graça Pereira iD http://orcid.org/0000-0001-7987-2562 Margarida Vilaça (iD) http://orcid.org/0000-0002-4349-8633 Gabriela Ferreira iD http://orcid.org/0000-0003-0993-5614 Marta Pereira iD http://orcid.org/0000-0001-7176-3775 Sara Faria iD http://orcid.org/0000-0001-9792-5816

Sara Monteiro (iD http://orcid.org/0000-0002-1389-3851

Rosário Bacalhau iD http://orcid.org/0000-0001-5030-5425

\section{References}

Applebaum, A. J., Bevans, M., Son, T., Evans, K., Hernandez, M., Giralt, S., \& DuHamel, K. (2016). A scoping review of caregiver burden during allogeneic HSCT: lessons learned and future directions. Bone Marrow Transplantation, 51(11), 1416-1422.

Beattie, S., \& Lebel, S. (2011). The experience of caregivers of hematological cancer patients undergoing a hematopoietic stem cell transplant: A comprehensive literature review. Psycho-Oncology, 20(11), 1137-1150.

Bocchi, S., \& Angelo, M. (2008). Entre a liberdade e a reclusão: O apoio social como componente da qualidade de vida do binómio cuidador familiar - pessoa dependente [Between freedom and reclusion: Social support as a quality-of-life component in the family caregiver-dependent person binomial]. Revista Latino-Americana de Enfermagem, 16, 15-23.

Brito, L. (2002). A saúde mental dos prestadores de cuidados a familiares idosos [The mental health of health care providers to the elderly]. Coimbra: Quarteto Editora.

Campbell, H., Hall, A., Sanson-Fisher, R., Barker, D., Turner, D., \& TaylorBrown, J. (2014). Development and validation of the Short-Form Survivor Unmet Needs Survey (SF-SUNS. ). Supportive Care in Cancer, 22, 1701-1709. doi:

Chen, S., Lai, Y., Liao, C., Huang, B., Lin, C., Fan, K., \& Chang, J. (2014). Unmet supportive care needs and characteristics of family caregivers of patients with oral cancer after surgery. Psycho-Oncology, 23(5), 569-577.

Cooke, L., Grant, M., Eldredge, D. H., Maziarz, R. T., \& Nail, L. M. (2011). Informal caregiving in Hematopoietic Blood and Marrow Transplant patients. European Journal of Oncology Nursing, 15(5), 500-507.

Deniz, H., \& Inci, F. (2015). The burden of care and quality of life of caregivers of leukemia and lymphoma patients following peripheric stem cell transplantation. Journal of Psychosocial Oncology, 33(3), 250-262.

El-Jawahri, A. R., Traeger, L. N., Kuzmuk, K., Eusebio, J. R., Vandusen, H. B., ... Jackson, V. A. (2015). Quality of life and mood of patients and family caregivers during hospitalization for hematopoietic stem cell transplantation. Cancer, 121, 951-959.

Extermann, M., Overcash, J., Lyman, G. H., Parr, J., \& Balducci, L. (1998). Comorbidity and functional status are independent in older cancer patients. Journal of Clinical Oncology, 16(4), 1582-1587.

Fitch, M. I., \& Maamoun, J. (2016). Unmet supportive care needs and desire for assistance in patients receiving radiation treatment: Implications for oncology nursing. Canadian Oncology Nursing Journal, 26(1), 53-597.

Friðriksdóttir, N., Saevarsdóttir, 凶., Halfdánardóttir, S. Í., Jónsdóttir, A., Magnúsdóttir, H., Ólafsdóttir, K. L., ... Gunnarsdóttir, S. (2011). 
Family members of cancer patients: Needs, quality of life and symptoms of anxiety and depression. Acta Oncologica, 50(2), 252-258.

Fujinami, R., Sun, V., Zachariah, F., Uman, G., Grant, M., \& Ferrell, B. (2015). Family caregivers' distress levels related to quality of life, burden, and preparedness. Psycho-Oncology, 24(1), 54-62.

Gaugler, J. E., Hanna, N., Linder, J., Given, C. W., Tolbert, V., Kataria, R. \& Regine, W. F. (2005). Cancer caregiving and subjective stress: A multi-site, multi-dimensional analysis. Psycho-Oncology, 14(9), 771-785.

Girgis, A., Lambert, S., \& Lecathelinais, C. (2011). The supportive care needs survey for partners and caregivers of cancer survivors: Development and psychometric evaluation. Psycho-Oncology, 20(4), 387-393.

Grant, M., Sun, V., Fujinami, R., Sidhu, R., Otis-Green, S., Juarez, G., ... Ferrell, B. (2013). Family caregiver burden, skills preparedness, and quality of life in non-small cell lung cancer. Oncology Nursing Forum, 40(4), 337-346.

Grimm, M., Zawacki, L., Mock, V., Krumm, S., \& Frink, B. (2000). Caregiver responses and needs: An ambulatory bone marrow transplant model. Cancer Practice, 8(3), 120-128.

Grov, E., Dahl, A., Moum, T., \& Fossa, S. (2005). Anxiety, depression, and quality of life in caregivers of patients with cancer in late palliative phase. Annals of Oncology, 16(7), 1185-1191.

Hair, J. F., Black, W., Babin, B., \& Anderson, R. (2010). Multivariate data analysis (7th ed.). Upper Saddle River, NJ: Prentice Hall.

Kim, J., Han, J. Y., Shaw, B., McTavish, F., \& Gustafson, D. (2010). The roles of social support and coping strategies in predicting breast cancer patients' emotional well-being: testing mediation and moderation models. Journal of Health Psychology, 15, 543-552. doi:

Kim, Y., Baker, F., Spillers, R. L., \& Wellisch, D. K. (2006). Psychological adjustment of cancer caregivers with multiple roles. PsychoOncology, 15(9), 795-804.

Kim, Y., Kashy, D. A., Spillers, R. L., \& Evans, T. V. (2009). Needs assessment of family caregivers of cancer survivors: Three cohorts comparison. Psycho-Oncology, 19(6), 573-582.

Kristjanson, L., \& White, K. (2002). Clinical support for families in the palliative care phase of hematologic or oncologic illness. Hematology/Oncology Clinics of North America, 16(3), 745-762.

Kurtin, S., Lilleby, K., \& Spong, J. (2013). Caregivers of multiple myeloma survivors. Clinical Journal of Oncology Nursing, 17(s6), 25-32.

La, I. S., \& Yun, E. K. (2017). Effects of stress appraisal on the quality of life of adult patients with multiple myeloma and their primary family caregivers in Korea. Psycho-Oncology, 26(10), 1640-1646.

Lambert, S. D., Harrison, J. D., Smith, E., Bonevski, B., Carey, M., Lawsin, C., ... Girgis, A. (2012). The unmet needs of partners and caregivers of adults diagnosed with cancer: A systematic review. BMJ Supportive \& Palliative Care, 2, 224-230.

Lapid, M., Atherton, P., Kung, S., Sloan, J., Shahi, V., Clark, M., \& Rummans, T. (2016). Cancer caregiver quality of life: Need for targeted intervention. Psycho-Oncology, 25(12), 1400-1407.

Lazarus, R. S., \& Folkman, S. (1984). Stress, appraisal, and coping. New York: Springer.

LeSeure, P., \& Chongkham-Ang, S. (2015). The experience of caregivers living with cancer patients: A systematic review and meta-synthesis. Journal of Personalized Medicine, 5(4), 406-439.

Madore, L. (2015). Caregiver-patient relationship and stress response in multiple myeloma (Doctoral Dissertation). Retrieved from: http:// digital.auraria.edu/AA00003750/00001

Marques, T. (2012). Doentes oncológicos e seus cuidadores informais: Estudo exploratório da qualidade de vida, distresse e estratégias de coping [Oncological patients and their informal caregivers: Exploratory study of quality of life, distress and coping strategies] (Master's thesis). Faculdade de Psicologia, Universidade de Lisboa, Lisboa.

Minaya, P., Baumstarck, K., Berbis, J., Goncalves, A., Barlesi, F., Michel, G., ... Auquier, P. (2012). The Caregiver Oncology Quality of Life questionnaire (CarGOQoL): Development and validation of an instrument to measure the quality of life of the caregivers of patients with cancer. European Journal of Cancer, 48(6), 904-911.

Mohile, S. G., Fan, L., Reeve, E., Jean-Pierre, P., Mustian, K., Peppone, L., ... Dale, W. (2011). Association of cancer with geriatric syndromes in older medicare beneficiaries. Journal of Clinical Oncology, 29(11), $1458-1464$.
Mohile, S. G., Xian, Y., Dale, W., Fisher, S. G., Rodin, M., Morrow, G. R., ... Hall, W. (2009). Association of a cancer diagnosis with vulnerability and frailty in older medicare beneficiaries. Journal of the National Cancer Institute, 101(17), 1206-1215.

Molassiotis, A., Wilson, B., Blair, S., Howe, T., \& Cavet, J. (2011a). Living with multiple myeloma: Experiences of patients and their informal caregivers. Supportive Care in Cancer, 19(1), 101-111.

Molassiotis, A., Wilson, B., Blair, S., Howe, T., \& Cavet, J. (2011b). Unmet supportive care needs, psychological well-being and quality of life in patients living with multiple myeloma and their partners. PsychoOncology, 20(1), 88-97.

Nolan, M., Keady, J., \& Grant, G. (1995). CAMI: A basis for assessment and support with family cares. British Journal of Nursing, 4(14), 822-826.

Northouse, L. L., Katapodi, M. C., Schafenacker, A. M., \& Weiss, D. (2012). The impact of caregiving on the psychological well-being of family caregivers and cancer patients. Seminars in Oncology Nursing, 28(4), 236-245.

O'Brien, T. B., \& DeLongis, A. (1997). Coping with chronic stress: An interpersonal perspective. In B. H. Gottlieb (Ed.), Coping with chronic stress (pp. 161-190). New York: Plenum Publishing Corporation.

Pais-Ribeiro, J. L., Silva, l., Ferreira, T., Martins, A., Meneses, R., \& Baltar, M. (2007). Validation study of a Portuguese version of the Hospital Anxiety and Depression Scale. Psychology, Health \& Medicine, 12, 225-237.

Pais-Ribeiro, J. L. (1999). Escala de Satisfação com o Suporte Social (ESSS) [Social Support Satisfaction Scale (SSSS. )]. Análise Psicológica, 3, 547-558.

Papastavrou, E., Charalambous, A., \& Tsangari, H. (2012). How do informal caregivers of patients with cancer cope: A descriptive study of the coping strategies employed. European Journal of Oncology Nursing, 16(3), 258-263.

Park, S. M., Kim, Y. J., Kim, S., Choi, J. S., Lim, H.-Y., Choi, Y. S., ... Yun, Y. H. (2010). Impact of caregivers' unmet needs for supportive care on quality of terminal cancer care delivered and caregiver's workforce performance. Supportive Care in Cancer, 18(6), 699-706.

Pereira, M. G., Ferreira, G., Pereira, M., Bacalhau, R., Monteiro, S., Faria, S., \& Vilaça, M. (2019). Validation of the Short-Form Survivor Unmet Needs Survey in Mieloma Patients and their Caregivers. Manuscript submitted for publication.

Pereira, M. G., Vilaça, M., Pereira, M., Bacalhau, R., Monteiro, S. Fernandes, B., ...., Ferreira, G. (in press). Validation of the Caregiver Oncology Quality of Life Questionnaire in Portuguese Caregivers of Myeloma Patients. Palliative \& Supportive Care.

Printz, C. (2011). Cancer caregivers still have many unmet needs. Cancer, 117(7), 1331-1331.

Quiñoa-Salanova, C., Porta-Sales, J., Monforte-Royo, C., \& Edo-Gual, M. (2019). The experiences and needs of primary family caregivers of patients with multiple myeloma: A qualitative analysis. Palliative Medicine, 33(5), 500-509. doi:

Rha, S., Park, Y., Song, S., Lee, C., \& Lee, J. (2015). Caregiving burden and health-promoting behaviors among the family caregivers of cancer patients. European Journal of Oncology Nursing, 19(2), 174-181.

Sanchéz, K., Ferreira, N., Dupas, G., \& Costa, D. (2010). Apoio social à família do paciente com câncer: Identificando caminhos e direções [Social support to the family of the cancer patient: Identifying ways and directions.]. Revista Brasileira de Enfermagem, 63, 290-299.

Schrank, B., Ebert-Vogel, A., Amering, M., Masel, E. K., Neubauer, M., Watzke, H., ... Schur, S. (2016). Gender differences in caregiver burden and its determinants in family members of terminally ill cancer patients. Psyco-Oncology, 25(7), 808-814.

Sequeira, C. (2010a). Adaptação e validação da Escala de Sobrecarga do Cuidador de Zarit [Adaptation and validation of Zarit Burden Interview Scale]. Referência, 12, 9-16.

Sequeira, C. (2010b). Cuidar de idosos com dependência física e mental [Caring for the elderly with physical and mental dependence]. Lisboa: Lidel-Edições Técnicas, Lda.

Simoneau, T. L., Mikulich-Gilbertson, S. K., Natvig, C., Kilbourn, K. Spradley, J., Grzywa-Cobb, R., ... Laudenslager, M. L. (2013). Elevated peri-transplant distress in caregivers of allogeneic blood or marrow transplant patients. Psycho-Oncology, 22(9), 2064-2070.

Sklenarova, H., Krümpelmann, A., Haun, M. W., Friederich, H.-C., Huber, J., Thomas, M., ... Hartmann, M. (2015). When do we need to care 
about the caregiver? Supportive care needs, anxiety, and depression among informal caregivers of patients with cancer and cancer survivors. Cancer, 121(9), 1513-1519.

Stenberg, U., Cvancarova, M., Ekstedt, M., Olsson, M., \& Ruland, C. (2014). Family caregivers of cancer patients: Perceived burden and symptoms during the early phases of cancer treatment. Social Work in Health Care, 53(3), 289-309.

Stenberg, U., Ruland, C. M., \& Miaskowski, C. (2009). Review of the literature on the effects of caring for a patient with cancer. PsychoOncology, 19(10), 1013-1025.

Swanberg, J. E. (2006). Making it work: Informal caregiving, cancer, and employment. Journal of Psychosocial Oncology, 24(3), 1-18.
Teixeira, R. J., \& Pereira, M. G. (2013). Psychological morbidity, burden, and the mediating effect of social support in adult children caregivers of oncological patients undergoing chemotherapy. PsychoOncology, 22(7), 1587-1593.

World Health Organization Quality of Life Group. (1994). Development of the WHOQOL: Rationale and current status. International Journal of Mental Health, 23, 24-56.

Zarit, S. H., \& Zarit, J. M. (1983). The memory and behaviour problems checklist - and the burden interview. Pennsylvania: Pennsylvania State University.

Zigmond, A., \& Snaith, R. (1983). The hospital anxiety and depression scale. Acta Psychiatrica Scandinavica, 67(6), 361-370. 